\title{
Expression of selected genes involved in steroidogenesis in the course of enucleation-induced rat adrenal regeneration
}

\author{
MARIANNA TYCZEWSKA, MARCIN RUCINSKI, AGNIESZKA ZIOLKOWSKA, \\ MARCIN TREJTER, MARTA SZYSZKA and LUDWIK K. MALENDOWICZ
}

Department of Histology and Embryology, Poznan University of Medical Sciences, Poznan, Poland

Received October 28, 2013; Accepted December 6, 2013

DOI: $10.3892 /$ ijmm.2013.1599

\begin{abstract}
The enucleation-induced (EI) rapid proliferation of adrenocortical cells is followed by their differentiation, the degree of which may be characterized by the expression of genes directly and indirectly involved in steroid hormone biosynthesis. In this study, out of 30,000 transcripts of genes identified by means of Affymetrix Rat Gene 1.1 ST Array, we aimed to select genes (either up- or downregulated) involved in steroidogenesis in the course of enucleation-induced adrenal regeneration. On day 1 , we found 32 genes with altered expression levels, 15 were upregulated and 17 were downregulated [i.e., $3 \beta$-hydroxysteroid dehydrogenase $(\mathrm{Hsd} 3 \beta)$, nuclear receptor subfamily 0 , group $\mathrm{B}$, member 1 ( $\mathrm{NrOb} 1$ ), cytochrome P450 aldosterone synthase (Cyp11b2) and sterol O-acyltransferase 1 (Soat1)]. On day 15, the expression of only 2 genes was increased and that of 3 was decreased. The investigated genes were clustered according to an hierarchical clustering algorithm and 4 clusters were obtained. Quantitative PCR (qPCR) confirmed the much lower mRNA expression levels of steroidogenic acute regulatory protein (StAR) during the regeneration process compared to the control, while the cholesterol side-chain cleavage enzyme (cholesterol desmolase; Cyp11a1) and Hsd $3 \beta$ genes presented similar expression profiles throughout the entire regeneration process. Cyp11b2 mRNA levels remained very low during the whole regeneration period. Fatty acid binding protein 6 (Fabp6) was markedly upregulated, whereas hormone-sensitive lipase (Lipe) was downregulated. The expression of Soat1 was lowest on regeneration day 1 and, subsequently, its expression increased from there on, reaching levels higher than the control. Dosage-sensitive sex reversal, adrenal hypoplasia critical region, on chromosome $\mathrm{X}$, gene 1 (Dax-1) mRNA levels were lowest on day 1 of the experiment;
\end{abstract}

Correspondence to: Dr Ludwik K. Malendowicz, Department of Histology and Embryology, Poznan University of Medical Sciences, 6 Swiecicki Street, PL-60781 Poznan, Poland

E-mail:1km@amp.edu.pl

Key words: adrenal regeneration, transcriptome analysis, microarray RNA, steroidogenesis, quantitative PCR, immunohistochemistry, rat however, throughout the entire experimental period, there were no statistically significant differences observed. After the initial decrease in steroidogenic factor 1 (Sf-1) mRNA levels observed on the 1st day of the experiment, a marked upregulation in its expression was observed from there on. Data from the current study strongly suggest the role of Fabp6, Lipe and Soat1 in supplying substrates of regenerating adrenocortical cells for steroid synthesis. Our results indicate that during the first days of adrenal regeneration, intense synthesis of cholesterol may occur, which is then followed by its conversion into cholesteryl esters. Moreover, our data demonstrated that in enucleationinduced regeneration, the restoration of genes involved in glucocorticoid synthesis is notably shorter than that of those involved in aldosterone synthesis.

\section{Introduction}

Steroid hormone production is the main function of adrenocortical cells. A basic substrate for steroidogenesis is free cholesterol which originates mainly from cholesteryl esters during a hydrolysis reaction. The recruitment of cholesteryl esters may be accomplished by the scavenger receptor class B, member 1 (Scarb1, also known as SR-B1) -mediated uptake of HDL and the subsequent conversion to free cholesterol by hormone-sensitive lipase (Lipe) in the cytosol. LDL cholesterol, on the other hand, is transported via receptor-mediated endocytosis and is then hydrolysed by acid cholesteryl esterase in lysosomes (1-7). Cholesteryl esters are also stored in cytosolic lipid droplets. Free cholesterol is also produced by de novo cholesterol biosynthesis from acetyl-coenzyme $\mathrm{A}$ in the endoplasmic reticulum by sterol O-acyltransferase 1 (Soat1); however, it only constitutes $20 \%$ of the substrate for steroidogenesis (8). In rodents, the principal source of cholesterol for steroidogenesis is circulating HDL. Both cholesterol hydrolysis and steroid synthesis are controlled by adrenocorticotropic hormone (ACTH) (9-11).

The enucleation of the adrenal gland consists of the removal of the cortex and medulla, leaving only the capsule with some zona glomerulosa and progenitor cells (12-14). It has been proven that cells left under the capsule after surgery do not express cytochrome P450 aldosterone synthase (Cyp11b2) or cytochrome P450 11 $\beta$-hydroxylase (Cyp11b1) (15). The two enzymes are markers of zona glomerulosa and zona fasciculata/reticularis cells, respectively. Therefore, it has 
been suggested that cortical cells of adrenal regeneration arise from de-differentiated zona glomerulosa cells which are left attached to the capsule following surgery, the phenotype of which is similar to that of cells of the zona intermedia, adrenal progenitor cells (14-17).

It is well known that adrenal enucleation results in an immediate decrease in plasma corticosterone levels, which leads to a marked compensatory hypersecretion of ACTH. The regeneration process is inhibited when one adrenal gland is left untouched and plasma corticosterone levels are normal and ACTH secretion remains under feedback control $(15,18,19)$. Corticosteroid hormone administration also prevents the regeneration of the cortex. It has been previously reported that during the first week of regeneration, the mRNA expression levels of aldosterone synthase and $11 \beta$-hydroxylase remain low (hybridization data). Cyp11b2 expression levels remain lower than those of the control up to day 30 of adrenal regeneration, whereas Cyp11b1 and 3 $\beta$-hydroxysteroid dehydrogenase $(\mathrm{Hsd} 3 \beta)$ levels are similar to those of the controls on the 20th and 30th day after enucleation (15).

In the present study, we aimed to determine the expression profiles of genes involved in steroidogenesis during enucleation-induced adrenocortical regeneration in rats. In order to accomplish this goal, the Affymetrix microarray method was used, as described in a recent study (20). This method enables the assay of numerous (approximately 30,000) genes which are involved in any aspect of adrenocortical function. Apart from well known genes with steroidogenic functions, such as steroidogenic acute regulatory protein (StAR, NM_031558.3), cholesterol side-chain cleavage enzyme (cholesterol desmolase, Cyp11a1, NM_017286.2), Hsd3ß (NM_001042619.1), steroid 21-hydroxylase (Cyp21a1, NM_057101.2), 11 $\beta$-hydroxylase (NM_012537.3) and aldosterone synthase (NM_012538.2), genes encoding enzymes which are indirectly involved in steroid hormone synthesis were also analyzed, such as fatty acid binding protein 6 (Fabp6, NM_017098.1), Lipe (NM_012859.1), Soat1 (Acat-1, NM_031118.1), nuclear receptor subfamily 0, group B, member 1 (Nr0b1, NM_053317.1), nuclear receptor subfamily 5, group A, member 1 (Nr5a1, NM_001191099.1).

\section{Materials and methods}

Animals, reagents and experimental design. Female Wistar rats (final body weight, 100-120 g) were used, obtained from the Laboratory Animal Breeding Center, Department of Toxicology, Poznan University of Medical Sciences. The animals were maintained under standardized conditions of light (14:10 h; light:dark cycle, illumination onset at 06.00 a.m.), at $23^{\circ} \mathrm{C}$, with free access to standard pellets and tap water. The study protocol was approved by the local ethics committee for animal studies. Unless not otherwise stated, all reagents were obtained from Sigma-Aldrich (St. Louis, MO, USA) or from Avantor Performance Materials Poland S.A. (Gliwice, Poland).

Under standard ketamine and xylazine anaesthesia, the rats were approached dorsally, in order to enucleate both adrenal glands according to a classic method (20). The operated rats were administered $0.9 \% \mathrm{NaCl}$ in their drinking water for 3 days. They were then sacrificed $1,2,3,5,8$ or 15 days after surgery, and their regenerated adrenals were immediately removed, freed of adherent fat and immersed in RNAlater. Other glands were frozen at $-20^{\circ} \mathrm{C}$ for gene expression studies [microarray and quantitative PCR (qPCR)] or fixed in Bouin's solution and embedded in paraffin for immunohistochemistry. Adrenals from sham-operated rats (day 1 post-surgery) were applied as the control adrenal glands.

RNA isolation. The applied methods were described in previous studies (21-25). Total RNA was extracted from the regenerated tissue with the use of TRI Reagent (Sigma-Aldrich) and then, purified on columns (Rneasy Mini Kit; Qiagen, Hilden, Germany), as previously described $(23,25-27)$. The amount of total mRNA was determined by optical density at $260 \mathrm{~nm}$ and its purity was estimated by a $260 / 280 \mathrm{~nm}$ absorption ratio (>1.8) on a NanodDrop spectrophotometer; Thermo Scientific, Walthman, MA, USA).

Reverse transcription. Reverse transcription was performed using AMV reverse transcriptase (Promega Corp., Madison, WI, USA) with oligo(dT) (PE Biosystems, Warrington, UK) primers at $42^{\circ} \mathrm{C}$ for $60 \mathrm{~min}$ on a thermocycler (UNO II; Biometra, Goettingen, Germany). The primers used were designed by Primer 3 software (Whitehead Institute for Biomedical Research, Cambridge, MA, USA) (Table I). The primers were purchased from the Laboratory of DNA Sequencing and Oligonucleotide Synthesis, Institute of Biochemistry and Biophysics, Polish Academy of Sciences, Warsaw, Poland.

Microarray RNA analysis. The Affymetrix ${ }^{\circledR}$ Rat Gene 1.1 ST Array (Affymetrix, Santa Clara, CA, USA) was followed as described in one of our recent studies (20). Total RNA was isolated from the adrenal glands with the use of TRI Reagent (Sigma-Aldrich) and then purified on columns (RNeasy Mini kit; Qiagen). RNA quantity and quality were analyzed by gel electrophoresis and spectrophotometry (NanoDrop ND-1000 spectrophotometer; Thermo Scientific). Total RNA (100 ng) was then subjected to 2 rounds of sense cDNA amplification (Ambion ${ }^{\circledR}$ WT Expression kit). The obtained cDNA was used for biotin labelling and fragmentation by Affymetrix GeneChip ${ }^{\circledR}$ WT Terminal Labeling and Hybridization (Affymetrix). By inserting the term 'steroidogenesis' as a query of the description of the regeneration course in the Gene Ontology (GO) database, 44 genes involved in steroidogenesis were identified as either up- or downregulated. The investigated genes were clustered according to an hierarchical clustering algorithm. The following clusters were obtained: i) genes presenting the highest expression levels from regeneration day 5 to regeneration day 15 (15 genes); ii) genes presenting the highest expression levels from day 3 to day 8 of the experiment (5 genes); iii) genes presenting the highest expression levels in the control glands and iv) genes presenting the highest expression levels at the beginning of the regeneration process. Gene expression values were presented as a heat map according to their hierarchical clustering. Since not all steroidogenesis-associated genes presented a 2 fold alteration in their expression levels under the applied experimental conditions, genes not identified by the GO database were also analyzed. 
Table I. Conventional RT-PCR and qPCR analyses.

\begin{tabular}{|c|c|c|c|c|c|}
\hline cDNA & $\begin{array}{c}\text { GenBank } \\
\text { accession no. }\end{array}$ & Primers & Primer sequence $\left(5^{\prime} \rightarrow 3^{\prime}\right)$ & Position & $\begin{array}{l}\text { PCR product } \\
\text { size (bp) }\end{array}$ \\
\hline Cyp11a1 & NM_017286 & $\begin{array}{l}\mathrm{S} \\
\mathrm{A}\end{array}$ & $\begin{array}{l}\text { GATGACCTATTCCGCTTTGC } \\
\text { GTTGGCCTGGATGTTCTTG }\end{array}$ & $\begin{array}{l}592-611 \\
930-948\end{array}$ & 357 \\
\hline StAR & NM_031558 & $\begin{array}{l}\mathrm{S} \\
\mathrm{A}\end{array}$ & $\begin{array}{l}\text { CCTGAGCAAAGCGGTGTCAT } \\
\text { GCAAGTGGCTGGCGAACTCTA }\end{array}$ & $\begin{array}{l}745-764 \\
911-931\end{array}$ & 187 \\
\hline $\operatorname{Hsd} 3 \beta$ & NM_001042619.1 & $\begin{array}{l}\mathrm{S} \\
\mathrm{A}\end{array}$ & $\begin{array}{l}\text { GGCATCTCTGTTGTCATC } \\
\text { GGTCTTCTTGTAGGAGTTG }\end{array}$ & $\begin{array}{l}375-392 \\
545-563\end{array}$ & 189 \\
\hline Cyp11b1 & NM_012537 & $\begin{array}{l}\mathrm{S} \\
\mathrm{A}\end{array}$ & $\begin{array}{l}\text { AGAGTATCCTCCCGCATCG } \\
\text { GCCAGTCTGCCCCATTTAG }\end{array}$ & $\begin{array}{l}311-329 \\
394-412\end{array}$ & 102 \\
\hline Cyp11b2 & NM_012538.2 & $\begin{array}{l}\mathrm{S} \\
\mathrm{A}\end{array}$ & $\begin{array}{l}\text { TGGCAGCACTAATAACTCAGG } \\
\text { AAAAGCCACCAACAGGGTAG }\end{array}$ & $\begin{array}{c}875-895 \\
1131-1150\end{array}$ & 276 \\
\hline Fabp6 & NM_017098.1 & $\begin{array}{l}\mathrm{S} \\
\mathrm{A}\end{array}$ & $\begin{array}{l}\text { GAAAGTGAGAAGAATTACGA } \\
\text { CATGATGTTGCCCCCAGAG }\end{array}$ & $\begin{array}{c}76-95 \\
210-228\end{array}$ & 153 \\
\hline Lipe & NM_012859.1 & $\begin{array}{l}\mathrm{S} \\
\mathrm{A}\end{array}$ & $\begin{array}{l}\text { GCCCTCCAAACAGAAACCC } \\
\text { AAATCCATGCTGTGTGAGAA }\end{array}$ & $\begin{array}{c}967-985 \\
1082-1101\end{array}$ & 135 \\
\hline Soat1 & NM_031118.1 & $\begin{array}{l}\mathrm{S} \\
\mathrm{A}\end{array}$ & $\begin{array}{l}\text { AAACAGTTGATAGCCAAGAAG } \\
\text { CCATTGTCCAGAGATGCAG }\end{array}$ & $\begin{array}{l}209-229 \\
327-345\end{array}$ & 137 \\
\hline $\begin{array}{l}\mathrm{NrOb} 1 \\
(\mathrm{Dax}-1)\end{array}$ & NM_053317.1 & $\begin{array}{l}\mathrm{S} \\
\mathrm{A}\end{array}$ & $\begin{array}{l}\text { AGAGTACGCCTATCTGAAG } \\
\text { ATCGGTGTTGATGAATCTC }\end{array}$ & $\begin{array}{l}1141-1159 \\
1321-1339\end{array}$ & 199 \\
\hline $\begin{array}{l}\text { Nr5a1 } \\
(\text { Sf-1) }\end{array}$ & NM_001191099.1 & $\begin{array}{l}\mathrm{S} \\
\mathrm{A}\end{array}$ & $\begin{array}{l}\text { ATGGCGGACCAGACCTTTATC } \\
\text { GCTGTCTTCCTTGCCGTACTG }\end{array}$ & $\begin{array}{c}949-969 \\
1093-1113\end{array}$ & 165 \\
\hline Hprt & NM_012583 & $\begin{array}{l}\mathrm{S} \\
\mathrm{A}\end{array}$ & $\begin{array}{l}\text { CAGTCAACGGGGGACATAAAAG } \\
\text { ATTTTGGGGCTGTACTGCTTGA }\end{array}$ & $\begin{array}{l}391-412 \\
515-536\end{array}$ & 146 \\
\hline
\end{tabular}

Cyp11a1, cholesterol desmolase; StAR, steroidogenic acute regulatory protein; Hsd3 $\beta$, 3 $\beta$-hydroxysteroid dehydrogenase; Cyp11b1, 11 $\beta$-hydroxylase; Cyp11b2, aldosterone synthase; Fabp6, fatty acid binding protein 6; Lipe, hormone-sensitive lipase; Soat 1, sterol O-acyltransferase 1; Nr0b1 (Dax-1), nuclear receptor subfamily 0; group B, member 1; Nr5a1 (Sf-1), nuclear receptor subfamily 5, group A, member 1; S, sense; A, antisense; Hprt, hypoxanthine phosphorybosyl transferase (reference gene).

qPCR. qPCR was performed using the LightCycler ${ }^{\circledR} 2.0$ instrument (Roche Diagnostics, Basel, Switzerland) with version 4.05 software. Using the primers presented in Table I, the YBR-Green detection system was applied. In each $20 \mu \mathrm{l}$ of reaction mixture, $4 \mu \mathrm{l}$ of template cDNA (standard or control), $0.5 \mu \mathrm{M}$ of each gene-specific primer and $3.5 \mu \mathrm{M} \mathrm{MgCl}_{2}$ (a concentration determined by pre-optimization experiments). LightCycler FastStart DNA Master SYBR-Green I mix (Roche) was used. The qPCR program included a 10-min denaturation step in order to activate the Taq DNA polymerase, followed by a 3-step amplification program: denaturation at $95^{\circ} \mathrm{C}$ for $10 \mathrm{sec}$, annealing at $56^{\circ} \mathrm{C}$ for $5 \mathrm{sec}$ and extension at $72^{\circ} \mathrm{C}$ for $10 \mathrm{sec}$. The specificity of the amplification products was determined by melting curve analysis $\left(0.1^{\circ} \mathrm{C} / \mathrm{sec}\right.$ transition rate).

Immunohistochemistry. A standard immunohistochemistry method (using peroxidase) with $\mathrm{ABC}$ reaction (avidin biotin complex) was used $(20,25,28)$. The adrenals were fixed in Bouin's solution for $24 \mathrm{~h}$ and embedded in paraffin. $6 \mu \mathrm{m}$-thick sections of adrenals were used. The sections were then boiled in citrate buffer ( $\mathrm{pH} 6 ; 2.5 \mathrm{~min}, 2.5 \mathrm{~min}, 3.5 \mathrm{~min}$ and $3 \times 20$ min cooling). The sections were incubated with the primary antibody for $1 \mathrm{~h}$ at room temperature (anti-Cyp11a1, anti-Cyp11b1, 1:200) or overnight at $4^{\circ} \mathrm{C}$ (anti-StAR, 1:200). All antibodies were purchased from Abcam (Cambridge, MA, USA) and Bioss (Scotland, UK). Subsequently, the sections were washed and incubated with the secondary (peroxidaseconjugated) antibody for $60 \mathrm{~min}$ at $37^{\circ} \mathrm{C}$. Peroxidase activity was detected using the DAB technique (liquid DAB substratechromogen system; Dako, Glostrup, Denmark). The nuclei were counterstained with haematoxylin. The control sections included similarly treated adjacent sections with the omission of the primary antibody.

Statistical analysis. Data are expressed as the means \pm SE and statistically significant differences between the control and experimental groups was assessed by the Student's t-test.

\section{Results}

Microarray analysis. Using the Affymetrix microarray method we examined the expression levels of approximately 30,000 genes in each sample of regenerated adrenals (days 1, 2, 3, 5, 8 and 15 after enucleation) and in the control glands 


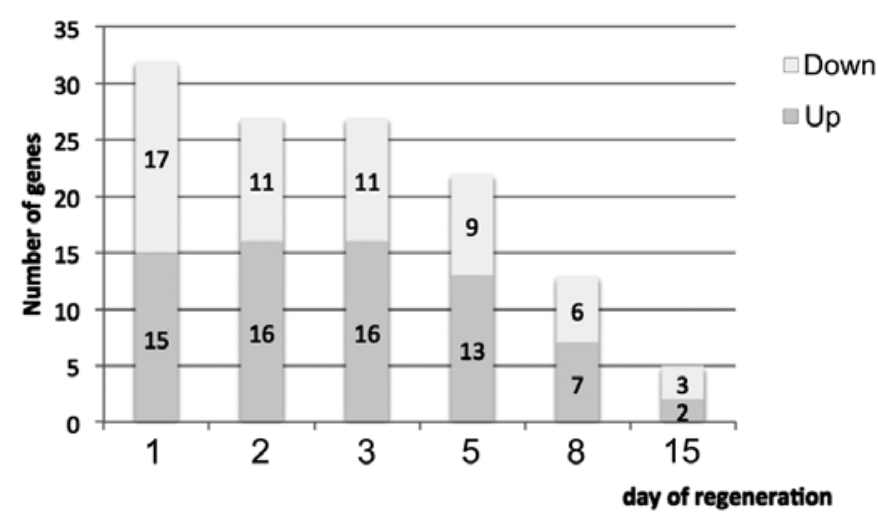

Figure 1. Affymetrix ${ }^{\circledast}$ Rat Gene 1.1 ST Array. Number of genes involved in steroidogenesis, which were found to be up-/downregulated by $>2$-fold during adrenal regeneration $(\mathrm{p}<0.05)$.
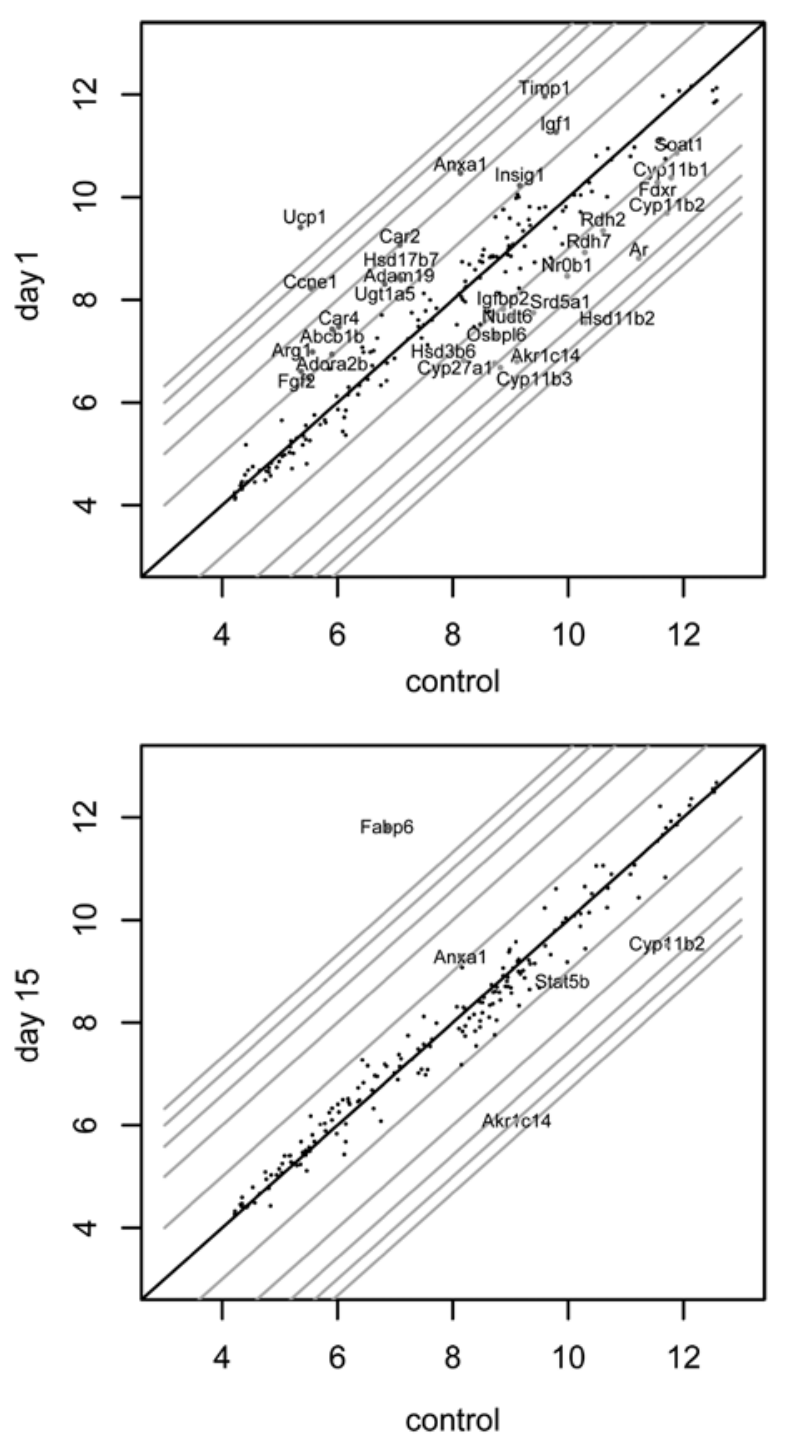

Figure 2. Affymetrix ${ }^{\circledR}$ Rat Gene 1.1 ST Array. Expression of genes involved in steroidogenesis during rat enucleation-induced adrenocortical regeneration. Scatter plot graphs show data for days 1 and 15 of adrenal regeneration, in relation to control glands. Grey lines mark statistically significant changes ( $>2$-fold change in expression, $\mathrm{p}<0.05$ ). Dots outside the parallel lines represent transcripts with an expression fold change $>2$. On day 1 following enucleation 15 genes were found to be upregulated contrary to day 15 where only 2 were found. On day 1 of adrenal regeneration, 17 genes were downregulated while on day 15 , only 3 were.
( 3 adrenals per day). The microarray data were compared by fold change calculations, relative to the control glands. From all up- or downregulated genes that were examined, only those involved in steroidogenesis were selected. The selection was performed using the Gene Ontology (GO) database, where the word 'steroidogenesis' was used as a query of the description of biological processes. It was noted that 32 genes involved in steroid hormone production were found to have altered expression levels on day 1 of regeneration (up-/downregulation by $>2$-fold, $\mathrm{p}<0.05$ ) (Fig. 1). Twenty-four hours after enucleation, only 15 genes were found upregulated, including the gene for insulin-like growth factor 1 (Igf1), insulin-induced gene 1 (Insig1), genes for cyclin E1 (Ccne1) and UDP glucuronosyltransferase 1 family, polypeptide A5 (Ugt5a1). At the same time point, the expression levels of 17 genes were decreased $(H s d 3 \beta$, Nr0b1, Cyp1 1b2 and Soat1). By contrast, increased expression levels were observed in only 2 genes, whereas 3 genes showed a decrease in expression on day 15 following adrenal enucleation (Fig. 2, scaterplot).

The expression levels of the above-mentioned genes were also presented as a heat map (Fig. 3). The investigated genes were clustered based on an hierarchical clustering algorithm. The following 4 clusters were obtained: i) 15 genes with the highest expression levels between days 5-15 of regeneration; ii) 5 genes with the highest expression levels between days 3-8 of the experiment; iii) 6 genes with the highest expression in the control glands; iv) genes with the highest expression at the beginning of the regeneration process. Signal intesities were expressed in a color scale, where green represents the upregulated expression, and red the downregulated expression levels relative to the control group. All these genes are listed in detail in Fig. 3. In addition, graphs depicting the expression profiles of several genes, represented the distinguished gene groups and were validated by qPCR (Fig. 3).

$q P C R$. For selected genes of known steroidogenic function, the microarray data were validated by qPCR (Fig. 4). As demonstrated, the mRNA expression levels of StAR were much lower during the regeneration process compared to the control. The Cyp11a1 and Hsd $3 \beta$ genes presented a similar expression profile during the regeneration process. On the 1st day after enucleation, the expression levels of both genes significantly decreased compared to those of the control $(\mathrm{p}<0.001)$. Moreover, on days 2 and 3 of regeneration, the expression levels remained low; however, between days 5-15 they increased and remained higher than those of the control. As depicted in Fig. 4, the Cyp11b1 mRNA levels were very low during the first 3 days of regeneration, but on days 8 and 15 of the experimental procedure, the expression levels reached similar levels to those of the control. The mRNA expression levels of Cyp11b2, on the other hand, were very low throughout the period following adrenal regeneration.

Among the genes that were indirectly involved in steroidogenesis, Fabp6 was markedly upregulated in the regenerating adrenals (Fig. 5). The highest expression levels of Fabp6 were observed on day 8 of regeneration $(\mathrm{p}<0.001)$. Its expression levels on day 1 of regeneration were similar to those of the control, but from day 2 until day 8 they significantly increased. On day 15, decreased Fabp6 mRNA levels were observed; however, in spite of this they were still much higher compared 

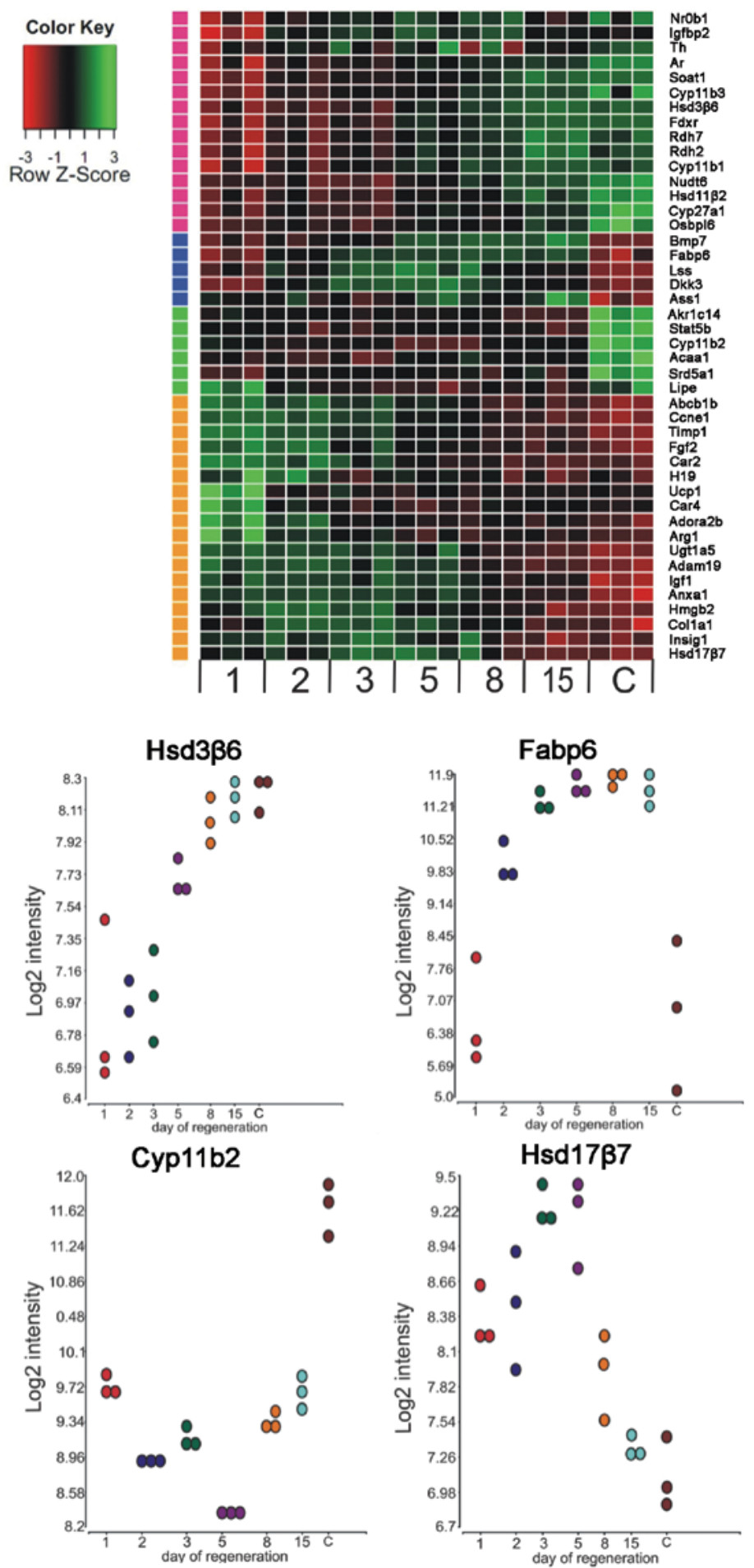

Figure 3. The heatmap presents microarray expression data of 52 genes involved in steroidogenesis. Raw expression data of each gene in regenerating adrenals along different days of the experiment (1,2,3,5,8 and 15) and in control glands (C) are shown. Signal intesities are expressed in a color scale where green represents the upregulated expression and red the downregulated expression levels relative to the control group (color bar). The investigated genes were clustered based on an hierarchical clustering algorithm. The following clusters were obtained: i) genes with the highest expression levels observed between days 5-15 of regeneration (15 genes: Nr0b1, Igfbp2, Th, Ar, Soat1, Cyp11b3, Hsd3ß6, Fdxr, Rdh7, Rdh2, Cyp11b1, Nudt6, Hsd11ß2, Cyp27a1, Osbp16); ii) genes with the highest expression levels observed between days 3-8 of the experiment (only 5 genes: Bmp7, Fabp6, Lss, Dkk3, Ass1); iii) genes with the highest expression levels observed in the control glands (only 6 genes: Akr1c14, Stat5b, Cyp11b2, Acaa1, Srd5a1, Lipe); iv) genes with the highest expression levels observed at the beginning of the regenerating process (Abcb1b, Ccne1, Timp1, Fgf2, Car2, H19, Ucp1, Car4, Adora2b, Arg1, Ugt1a5, Adam19, Igf1, Anxa1, Hmgb2, Col1a1, Insig1, Hsd17ß7). Dot graphs presents the expression profiles of of 4 selected genes (Hsd3 36 , Fabp6, Cyp11b2, Hsd17ß3) as a representative of each heat map cluster (validated by qPCR).

to those of the control. Contrary to Fabp6, Lipe gene expression levels, on day 1 following enucleation, were the highest compared to those of the control. Thereafter, they gradually decreased, failing to reach the control values. Soat 1 expression levels were the lowest on day 1 of regeneration and subsequently increased, reaching values higher than those in the control 

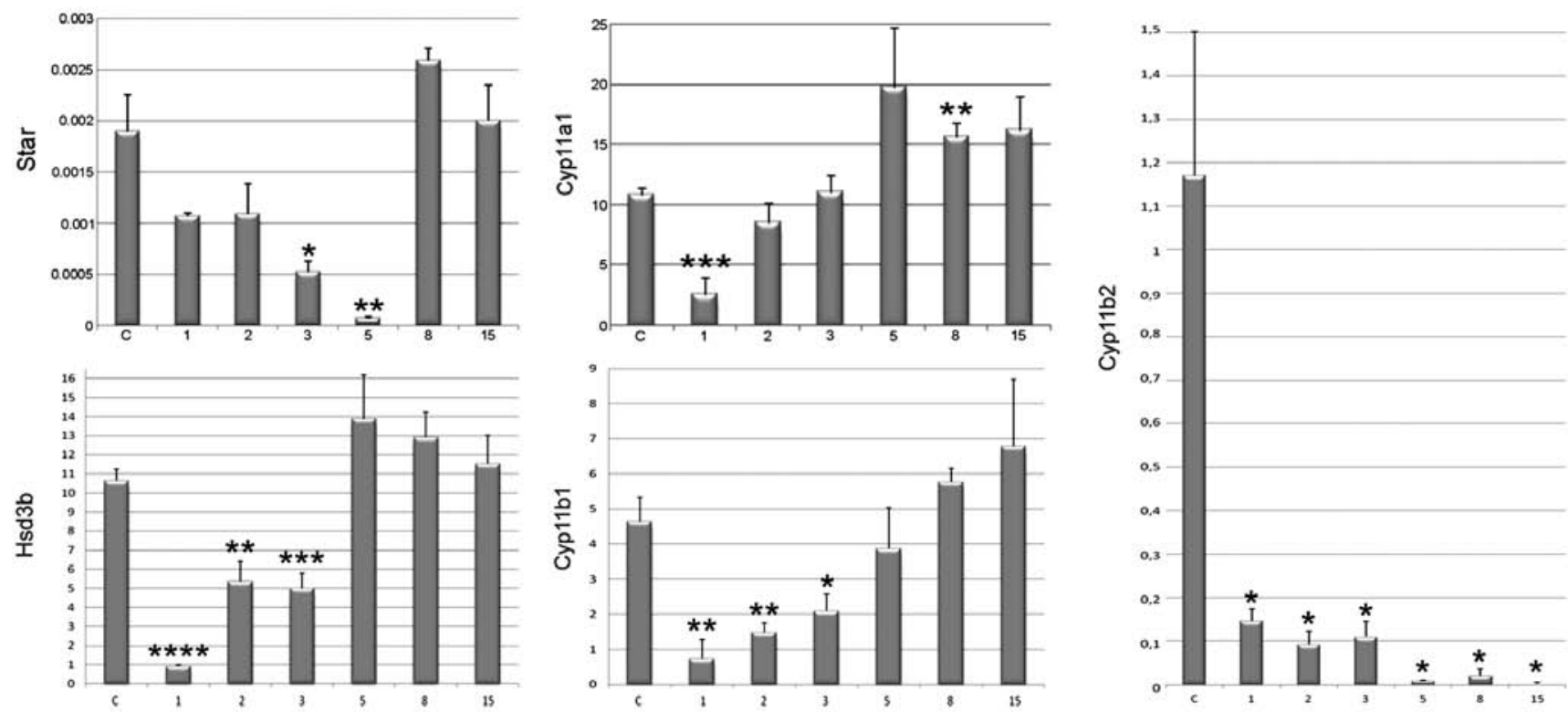

Figure 4. qPCR (validation of matrix data) of StAR, Cyp11a1, Cyp11b2, Hsd3 $\beta$ and Cyp11b1 mRNA expression levels in the rat adrenal cortex regeneration relative to the control adrenals. Bars represent the means $\pm \mathrm{SE}(\mathrm{n}=3)$. Statistically significant differences relative to the control group: ${ }^{*} \mathrm{p}<0.05 ;{ }^{* * *} \mathrm{p}<0.02 ;{ }^{* * * *} \mathrm{p}<0.01 ;$ ***** $\mathrm{p}<0.001$.
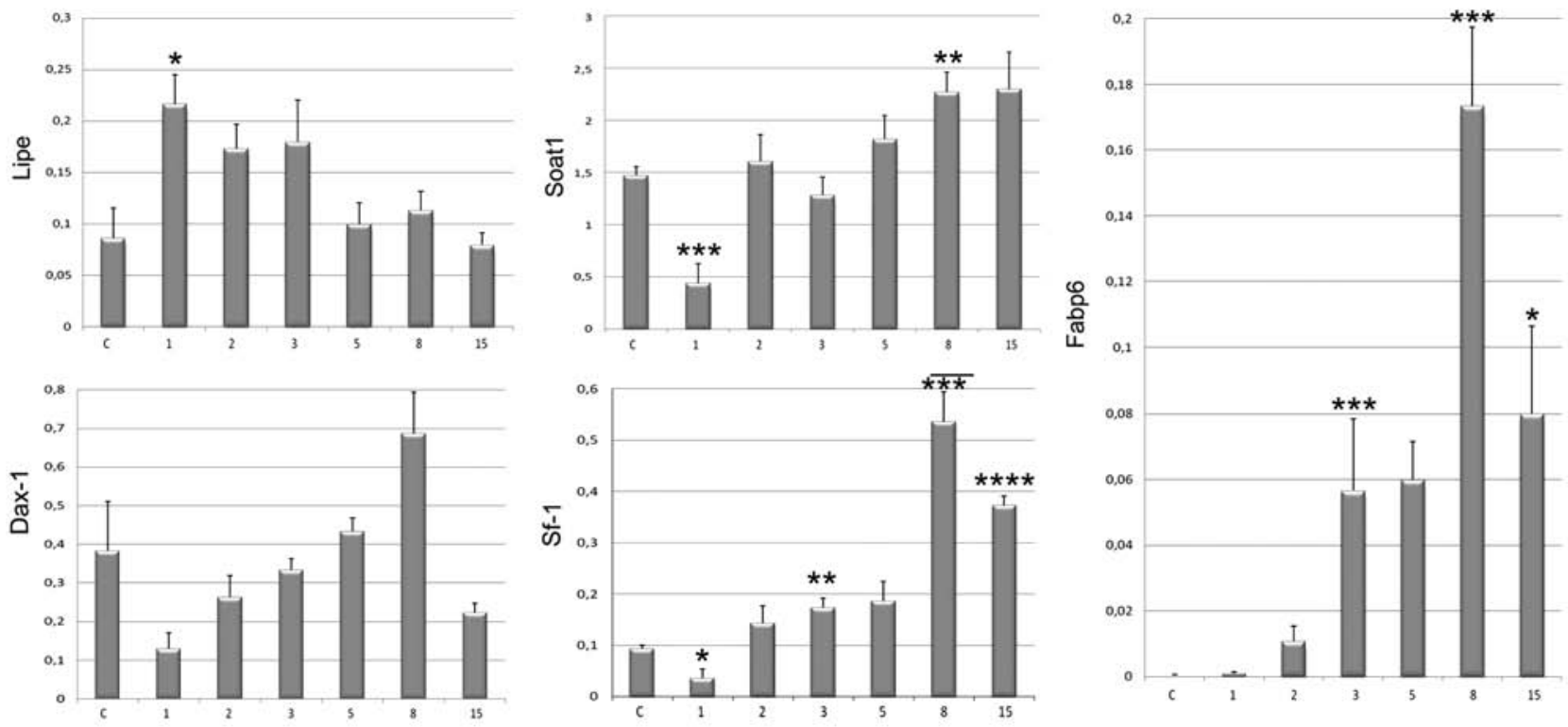

Figure 5. qPCR (validation of matrix data) of Lipe, Soat1, Fabp6, Dax-1 and Sf-1 mRNA expression levels in the rat adrenal cortex regeneration relative to the control adrenals. Bars represent the means $\pm \mathrm{SE}(\mathrm{n}=3)$. Statistically significant differences relative to the control group: ${ }^{*} \mathrm{p}<0.05 ;{ }^{* * *} \mathrm{p}<0.02 ;{ }^{* * * *} \mathrm{p}<0.01 ;{ }^{* * * * *} \mathrm{p}<0.001$.

adrenals. Dosage-sensitive sex reversal, adrenal hypoplasia critical region, on chromosome X, gene 1 (Dax-1) mRNA levels were the lowest on day 1 of the experiment; however, during the entire experimental period, the differences were statistically insignificant. After an initial drop in the expression levels on day 1 of the experiment, Sf-1 mRNA levels underwent a notable upregulation, particularly on days 8 and 15 after enucleation, where values were 4 - to 5-fold higher than those in the control adrenals.
Immunohistochemistry. Immunohistochemistry revealed Cyp11a1-, Cyp11b1- and StAR-like immunoreactivity in the cytoplasm of all adrenocortical cells of control rats (Fig. 6). At the beginning of enucleation-induced adrenal regeneration (days 2-5) StAR-like immunoreactivity was not observed in cells adjacent to the capsule. It should be mentioned that these cells express visinin-like immunoreactivity [visinin-like 1 (Vsn11), NM_012686.2], a marker of zona glomerulosa cells (data not shown). Cyp11a1-like and Cyp11b1-like immuno- 


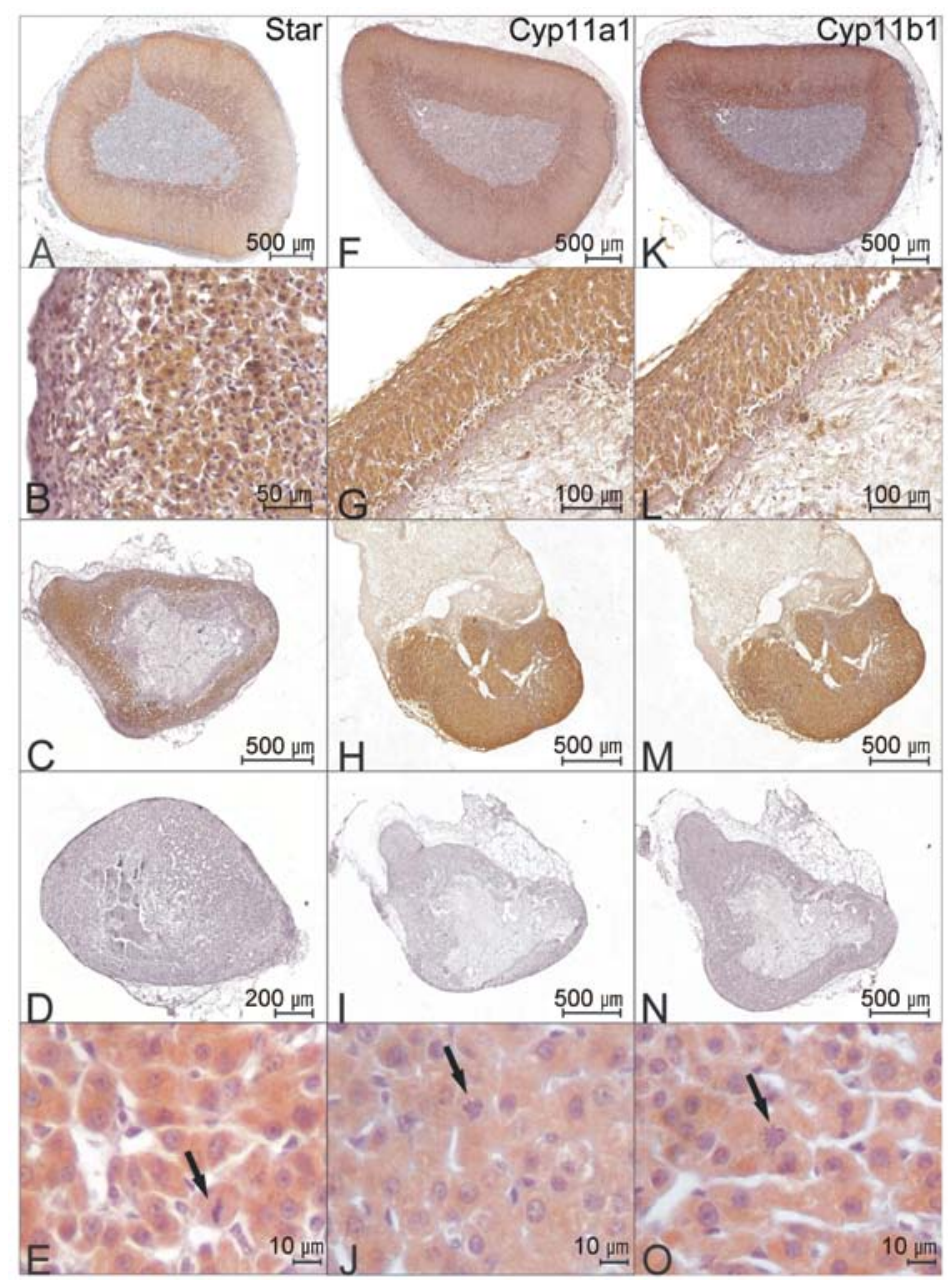

Figure 6. Immunoreactivity in regenerating rat adrenal gland cells against (A-E) StAR, (F-J) Cyp1la1 and (K-O) Cyp1 1b1-like. (A, F and K) Cytoplasmic staining of adrenocortical cells in an intact control gland. (B, G and L) Cytoplasmic staining of adrenocortical cells on the 3rd day of regeneration. (C, $\mathrm{H}$ and $\mathrm{M}$ ) Cytoplasmic staining of adrenocortical cells on the 5th day of regeneration. (E, J and O) Higher magnification of regenerated immunostained adrenocortical cells on experimental day 5. Arrows show the mitotic divisions. (D, I and N) Control slides on day 5 following enucleation - no immunostaining is present. Sections were counterstained with hematoxylin.

reactivity was observed in all adrenocortical cells of the regenerating cortex.

\section{Discussion}

Enucleation-induced adrenal regeneration is a fine model of rapid adrenal cell growth, in which stages of proliferation, differentiation and specialization occur in a relatively short time. Therefore, in this study, using this experimental model, we aimed to characterize the expression profiles of genes directly and indirectly involved in steroidogenesis. The global expression profiles of genes and of selected genes involved in steroidogenesis were evaluated by Affymetrix microarray analysis, as well as by qPCR and immunohistochemistry, as described in one of our recent studies (20). We used the GO database with the following criteria: use of the word 'steroidogenesis' in the search bar of the description of biological processes and with a qualification cut-off of $\mathrm{p}<0.05$ and a $>2$-fold change in expression, led to the selection of 44 genes involved in steroid hormone production that were either up-/ downregulated. The number of selected genes decreased during adrenal regeneration. On the 1st day following enucleation,
15 genes were found upregulated, while 17 were downregulated. The genes with elevated expression levels included Insig1, which may play a role in regulating intracellular cholesterol concentrations; Ccnel, involved in cellular growth stimulation; and Ugt5a1, coding UDP-glucuronosyltransferase, an enzyme of the glucuronidation pathway which transforms small lipophilic molecules into water-soluble metabolites. By contrast, on day 15 of adrenocortical regeneration, the expression levels of only 2 genes were increased (e.g., Fabp6), while 3 genes were found downregulated [Cyp11b2; aldo-keto reductase family 1, member C14 (Akr1c14), involved in steroid metabolism; and signal transducer and activator of transcription 5B (Stat5b), a transcription factor which mediates the function of growth hormones and several interleukins]. Genes indirectly involved in steroidogenesis prevailed among all the genes selected by the GO database and they are responsible for providing substrates for steroidogenesis. This group combines, for example, genes involved in the uptake, transport and hydrolysis of lipoproteins (Fabp6, Lipe, Ugt1a5 and Insig1), or those involved in cholesterol synthesis [lanosterol synthase (2,3-oxidosqualenelanosterol cyclase) (Lss)] or in mitochondrial ion transport [uncoupling protein 1 (Ucp1) and ferredoxin reductase (Fdxr)]. 
Of note, the GO database with search descriptor 'steroidogenesis' only revealed some genes directly involved in steroid hormone production, for example the Hsd $3 \beta$ gene, Cyp11b1 and Cyp11b2, whereas other genes, such as StAR and Cyp11a1 were not selected. Thus, the data obtained from the GO database requires careful analysis to identify specific genes, not identified by GO analysis.

As demonstrated in the current study, adrenal enucleation in rats resulted in a rapid and marked decrease in the expression levels of the prevailing number of steroidogenic genes (until day 5), while less or more notable increases in their mRNA levels were observed in the following days. These data are in agreement with those of earlier reports. For example, labelled areas of cells which expressed Cyp11b1 and Cyp11b2 mRNA remained very small during the first days post-surgery (hybridization and immunohistochemistry data) $(15,29,30)$. The labelled areas of the cells which expressed Cyp11b1 and Hsd $3 \beta$ mRNA increased between days 5 and 10 of regeneration, compared to day 2, and were comparable to those of the control on day 20 of the experiment. On the other hand, labelled areas of the cells which expressed Cyp11b2 mRNA were smaller than those of the control even on day 30 of regeneration.

In the present study, microarray data were validated by qPCR and such an approach provided a more precise characterization of gene expression involved in steroidogenesis. The StAR gene encodes a protein involved in the acute regulation of steroid hormone synthesis. This protein is responsible for the transport of cholesterol from the outer to the inner mitochondrial membrane. An earlier study revealed notable downregulation of both StAR gene and protein expression levels in regenerating rat adrenals on experimental day 5 (31). The current study confirmed these data and revealed a significant upregulation in gene expression between experimental days 8-15. During the initial stages of regeneration, StARlike immunoreactivity was absent in capsule-adjacent cells (Fig. 5C), while cells of the deeper layers of the regenerating cortex exhibited an intense cytoplasmic reaction.

Cyp11a1 (cholesterol desmolase) gene expression levels were notably downregulated only on day 1 post-adrenal enucleation, which was followed by prompt and marked increases in the following days (even exceeding values found in the control glands). During the course of regeneration, immunohistochemistry revealed Cyp11a1-like immunoreactivity in all adrenocortical cell cytoplasms. These data suggest that the restoration of Cyp11al gene expression levels occurs very rapidly during rat adrenal gland regeneration and may be necessary in order to maintain a suitable level of steroidogenesis, which depends on the pregnenolone formation rate.

In rats, adrenal enucleation has been shown to result in a marked decrease in Hsd $3 \beta$ gene expression on day 2 following surgery and Hsd $3 \beta$ mRNA levels gradually increased between days 5-10 of the experiments (15). Our observations confirmed this earlier report.

Aldosterone synthase gene expression was described in rats during enucleation-induced adrenal regeneration, by Engeland et al $(15,29,30)$. The expression of this gene serves as a marker of the adrenal zona glomerulosa. By means of in situ hybridization, following enucleation, they observed a marked decrease in Cyp11b2 gene expression levels between days 2-20. The present study confirmed this observation and suggested that the morphofunctional maturation of zona glomerulosa in regenerating adrenals involves a very long process, compared with the zona fasciculata cells. Thus, the restoration of the mineralocorticoid synthesis pathway is notably delayed, when compared with that of the glucocorticoid pathway. These observations were supported by the quantification of aldosterone and corticosterone blood levels in the rats. In animals with regenerating adrenal glands, the restoration of blood corticosterone levels to those of the control values was notably shorter when compared with aldosterone concentrations $(32,33)$.

Of the enzymes involved in the glucocorticoid synthesis pathway, Cyp11b1 (11 $\beta$-hydroxylase) gene expression levels were examined, as its protein product is responsible for the transformation of 11-deoxycorticosterone (11-DOC) into corticosterone. As previously reported, $11 \beta$-hydroxylase-like immunoreactivity was expressed during the first week following enucleation, reflecting the presence of fasciculata cells (30). The current study revealed that Cyp11b1 gene expression levels during adrenal regeneration were low until day 5 following surgery and subsequently increased reaching values comparable to those of the control adrenals.

According to the above discussion, in enucleation-induced adrenal regeneration, after a rapid decrease, the expression levels of genes which are directly involved in glucocorticoid synthesis reach control levels or even higher around experimental day 5. Contrary to glucocorticoid synthesis, even after day 15 of regeneration, Cyp11b2 gene expression levels remain lower than those of the control. These time differences regarding the recovery of expression levels of genes responsible for corticosterone and aldosterone synthesis may depend on high proliferation, as well as on the varying differentiation rates of zona glomerulosa cells and zona fasciculata cells. It is possible that the proliferation and differentiation of these cells prevent the expression of genes regulating their highly specific function, in other words aldosterone synthesis.

It is well known that enucleation of adrenals results in profound changes in the expression profiles of genes directly involved in steroidogenesis. However, to the best of our knowledge, no data are available on gene expression profiling indirectly involved in this process. This group includes, among others, genes encoding proteins which bind, transport and metabolize fatty acids required for steroidogenesis. Fabp6 is a member of the FABP superfamily, which was detected in enterocytes of the ileum, luteal cells, as well as steroid-producing cells of the adrenal glands. Experimental data have suggested that it may mediate steroid transport and metabolism in steroid-producing cells $(34,35)$. Using both microarray analysis and qPCR, in this study, we found that during rat adrenal regeneration, Fabp6 mRNA expression levels notably increased, reaching levels significantly higher than those of the controls. Thus, the expression levels of the Fabp6 gene in adrenal regeneration are similar to those of genes directly involved in steroid hormone synthesis.

The adrenal steroid hormones are synthesized from cholesteryl esters, derived mostly from plasma HDL or LDL lipoproteins. Cholesterol uptake is mediated by specific receptors, Scarb1 and low density lipoprotein receptor (Ldlr) (.5,36-39). Our microarray analysis of Scarb1 and Ldlr genes failed to demonstrate significant changes in their expression levels during rat adrenal regeneration. On the other hand, 
during regeneration days 2-8, Lss gene expression levels were found to be high. Lss codes lanosterol synthase which catalyzes the cyclization of squalene to lanosterol during the biosynthesis of cholesterol from acyl-CoA. Lss expression levels were found significantly higher (by $>2$ to 3 -fold higher) than those of the control (microarray data not shown), suggesting that the source of cholesterol in adrenal cell regeneration may be de novo cholesterol synthesis rather than its uptake from lipoproteins, at least during the first days of regeneration. This is considered a very interesting finding, since it is well known that in a normal rat adrenal gland, only $20 \%$ of cholesterol originates from de novo synthesis in the endoplasmic reticulum $(8,40,41)$.

Lipe is a major cholesterol hydrolase of the adrenal glands. It cleaves cholesterol esters, stores triglycerides, diacylglycerides, monoacylglycerides, fatty acids and phospholipids that are also found in other tissues, such as the liver, white adipose tissue, the brain, kidneys and heart (42-47). In the current study, with the use of microarray analysis, we revealed that the expression profile of the Lipe gene was not altered significantly in adrenal cell regeneration during the examined period. However, the results from qPCR revealed a significant upregulation of Lipe mRNA levels on day 1 of regeneration compared to the control, followed by a gradual decrease in the expression levels observed in the control rats. This finding suggests that Lipe is involved in supplying regenerating adrenocortical cells with cholesterol for steroid production. Previous studies $(4,48)$ have indicated that Lipe is a major enzyme of the adrenal glands. Lipe-deficient adrenal glands of mice are characterized by the accumulation of lipid droplets in zona glomerulosa and fasciculata cells and by the agglomeration of necrotic lipoid cells near the medulla, as well as between medulla cells. Although these morphological changes do not significantly influence basal corticosterone expression levels, in Lipe-deficient mice, the response to ACTH stimulation is impaired. In this case, free cholesterol for steroid production may be provided by a compensatory decrease in Soat1 activity or an increase in LDL uptake or de novo synthesis of cholesterol (4). On the other hand, Osuga et al reported that Lipe deficiency had no effect on the adrenal corticosterone production under ACTH-stimulated conditions (49). Shen et al provided evidence of the interaction of Lipe with StAR in the transfer process of cholesterol in adrenocortical cells (50).

Recent data presented by Ohta et al (51) suggested that neutral cholesterol ester hydrolase 1 (Nceh1,NM_001127524.2) is an additional esterase of lipid metabolism in mouse adrenal glands. Lipe deficiency led to great limitations in cholesterol hydrolase activity in these cells; however, the additional inactivation of the Nceh1 gene completely inhibited esterase activity. Nceh1/Lipe double-deficient mice present with enlarged adrenal glands. Although the current study did not include qPCR data on Nceh1 expression levels in rat adrenal gland regeneration, microarray analysis demonstrated no significant changes in the expression profile of the Nceh1 gene during adrenal regeneration (data not shown).

An important result of the present study involves Soat1, the gene expression profile of which is opposite to that of Lipe. The expression levels of this gene were very low on day 1 after adrenal enucleation and were subsequently increased to levels higher than those observed in the control adrenals. Soatl belongs to the acyltransferase family and is localized on the membranes of the endoplasmic reticulum, where it catalyzes the conversion of free cholesterol and fatty acyl-CoA to cholesteryl esters. Soat1-deficient mice are characterized by markedly reduced cholesteryl ester levels in the adrenocortical cells; however, their response to ACTH challenge remains unaffected (52). The results of the current study suggest that Soat1 may play a role in the storage of cholesteryl esters in lipid droplets during the adrenocortical cell regeneration process; such lipid vacuoles were observed form day 5 of the experiment.

The Nr5a1 gene, which encodes steroidogenic factor 1 (Sf-1) and the NrOb1 gene, which encodes transcription factor Dax-1 have been documented as 2 genes of critical importance in the regulation of adrenal development and function. In the present study, their expression profiles were characterized during rat enucleation-induced adrenal regeneration. According to the obtained microarray data, Sf-1 expression was decreased compared to that of the control during rat adrenal regeneration. However, the results from qPCR demonstrated an upregulation of Sf-1 gene expression commencing from day 3 of regeneration. On days 8 and 15 , its expression levels were significantly higher than those in the control adrenals. On the other hand, the expression levels of the Dax-1 gene presented no change when compared to the control on a daily basis during the period of adrenal regeneration. As is known, both genes interact with each other and regulate the development and function of adrenocortical cells. Mutations in either gene result in the defective function of both human and mouse adrenal glands (53-57). Our data suggest that the Sf-1 gene plays an important role in rat enucleation-induced adrenal regeneration.

Overall, our results indicate that the expression of several genes directly and indirectly involved in steroidogenesis is altered during rat adrenal regeneration. Our data strongly suggest that Fabp6, Lipe and Soat1 play a role in supplying regenerating adrenocortical cell with substrates for steroid synthesis. All genes examined in the current study were either found to be up- or downregulated, as indicated by their mRNA expression level changes. Our results indicated that during the first days of adrenal regeneration, an intense synthesis of cholesterol may occur, which is then supplemented by the conversion of cholesterol into cholesteryl esters and stored in lipid droplets, which were already visible on day 5 following enucleation (20).

\section{Acknowledgements}

This study is in partial fulfillment of the Ph.D. thesis requirement of the Poznan University of Medical Sciences for M. Tyczewska. This study was supported by a grant (no. N401 334639) from the National Science Centre, Poland.

\section{References}

1. Balasubramaniam S, Goldstein JL and Brown MS: Regulation of cholesterol synthesis in rat adrenal gland through coordinate control of 3-hydroxy-3-methylglutaryl coenzyme A synthase and reductase activities. Proc Natl Acad Sci USA 74: 1421-1425, 1977.

2. Nishikawa T, Mikami K, Saito Y, Tamura Y and Kumagai A: Studies on cholesterol esterase in the rat adrenal. Endocrinol 108: 932-936, 1981.

3. Gwynne JT and Mahaffee DD: Rat adrenal uptake and metabolism of high density lipoprotein cholesteryl ester. J Biol Chem 264: 8141-8150, 1989. 
4. Li H, Brochu M, Wang SP, Rochdi L, Côté M, Mitchell G and Gallo-Payet N: Hormone-sensitive lipase deficiency in mice causes lipid storage in the adrenal cortex and impaired corticosterone response to corticotropin stimulation. Endocrinol 143 : 3333-3340, 2002.

5. Azhar S and Reaven E: Scavenger receptor class BI and selective cholesteryl ester uptake: partners in the regulation of steroidogenesis. Mol Cell Endocrinol 195: 1-26, 2002.

6. Connelly MA and Williams DL: SR-BI and HDL cholesteryl ester metabolism. Endocr Res 30: 697-703, 2004.

7. Miller WL and Bose HS: Early steps in steroidogenesis: intracellular cholesterol trafficking. J Lipid Res 52: 2111-2135, 2011.

8. Kraemer FB: Adrenal cholesterol utilization. Mol Cell Endocrinol 265-266: 42-45, 2007.

9. Trzeciak WH and Boyd GS: Activation of cholesteryl esterase in bovine adrenal cortex. Eur J Biochem 46: 201-207, 1974.

10. Malendowicz LK: A correlated steorological and functional studies on the long-term effects of ACTH on rat adrenal cortex. Folia Histochem Cytobiol 24: 203-211, 1986.

11. Schimmer BP, Cordova M, Cheng H, Tsao A, Goryachev AB, Schimmer AD and Morris Q: Global profiles of gene expression induced by adrenocorticotropin in $\mathrm{Y} 1$ mouse adrenal cells. Endocrinology 147: 2357-2367, 2006.

12. Greep RO and Deane HW: Histological, cytochemical and physiological observations on the regeneration of the rat's adrenal gland following enucleation. Endocrinology 45: 42-56, 1949.

13. Ingle DJ and Higgins GM: Regeneration of the adrenal gland following enucleation. Am J Med Sci 196: 232-239, 1938.

14. Mitani F, Mukai K, Miyamoto H, Suematsu M and Ishimura Y: The undifferentiated cell zone is a stem cell zone in adult rat adrenal cortex. Biochim Biophys Acta 1619: 317-324, 2003

15. Engeland WC and Levay-Young BK: Changes in the glomerulosa cell phenotype during adrenal regeneration in rats. Am J Physiology 276: R1374-R1382, 1999.

16. Mitani F, Suzuki H, Hata J, Ogishima T, Shimada $H$ and Ishimura Y: A novel cell layer without corticosteroid-synthesizing enzymes in rat adrenal cortex: histochemical detection and possible physiological role. Endocrinology 135: 431-438, 1994.

17. Mitani F, Ogishima T, Miyamoto $\mathrm{H}$ and Ishimura Y: Localization of P450aldo and $\mathrm{P} 45011$ beta in normal and regenerating rat adrenal cortex. Endocr Res 21: 413-423, 1995.

18. Holzwarth MA, Shinsako J and Dallman MF. Adrenal regeneration. Time course, effect of hypothalamic hemi-islands and response to unilateral adrenalectomy. Neuroendocrinology 31 : $168-176,1980$

19. Buckingham JC and Hodges JR: Interrelationships of pituitary and plasma corticotrophin and plasma corticosterone in adrenalectomized and stressed, adrenalectomized rats. J Endocrinol 63 : 213-222, 1974.

20. Tyczewska M, Rucinski M, Trejter M,Ziolkowska A, Szyszka M and Malendowicz LK: Angiogenesis in the course of enucleationinduced adrenal regeneration-expression of selected genes and proteins involved in development of capillaries. Peptides 38: 404-413, 2012

21. Albertin G, Carraro G, Parnigoto PP, Conconi MT,Ziolkowska A, Malendowicz LK and Nussdorfer GG: Human skin keratinocytes and fibroblasts express adrenomedullin and its receptors, and adrenomedullin enhances their growth in vitro by stimulating proliferation and inhibiting apoptosis. Int J Mol Med 11: 635-639, 2003.

22. Tortorella C, Macchi C, Spinazzi R, Malendowicz LK, Trejter M and Nussdorfer GG: Ghrelin, an endogenous ligand for the growth hormone-secretagogue receptor, is expressed in the human adrenal cortex. Int J Mol Med 12: 213-217, 2003.

23. Rucinski M, Albertin G, Spinazzi R, Ziolkowska A, Nussdorfer GG and Malendowicz LK: Cerebellin in the rat adrenal gland: gene expression and effects of CER and [des-Serl] CER on the secretion and growth of cultured adrenocortical cells. Int J Mol Med 15: 411-415, 2005.

24. Rucinski M, Andreis PG, Ziolkowska A, Nussdorfer GG and Malendowicz LK: Differential expression and function of beacon in the rat adrenal cortex and medulla. Int J Mol Med 16: 35-40, 2005.

25. Ziolkowska A, Rucinski M, Tortorella C, Tyczewska M, Nussdorfer GG and Malendowicz LK: Cultured rat calvarial osteoblast-like cells are provided with orexin type 1 receptors. Int J Mol Med 20: 779-782, 2007.
26. Rucinski M, Ziolkowska A, Tyczewska M and Malendowicz LK: Expression of prepro-ghrelin and related receptor genes in the rat adrenal gland and evidences that ghrelin exerts a potent stimulating effect on corticosterone secretion by cultured rat adrenocortical cells. Peptides 30: 1448-1455, 2009.

27. Albertin G, Rucinski M, Carraro G, Forneris M, Andreis P, Malendowicz LK and Nussdorfer GG: Adrenomedullin and vascular endothelium growth factor genes are overexpressed in the regenerating rat adrenal cortex, and AM and VEGF reciprocally enhance their mRNA expression in cultured rat adrenocortical cells. Int J Mol Med 16: 431-435, 2005.

28. Hochol A, Belloni AS, Rucinski M, Ziolkowska A, Di Liddo R, Nussdorfer GG and Malendowicz LK: Expression of neuropeptides $\mathrm{B}$ and $\mathrm{W}$ and their receptors in endocrine glands of the rat. Int J Mol Med 18: 1101-1106, 2006.

29. Engeland WC, Levay-Young BK, Paul JA and Fitzgerald DA Expression of cytochrome P450 aldosterone synthase and 11 beta-hydroxylase mRNA during adrenal regeneration. Endocr Res 21: 449-454, 1995

30. Engeland WC, Gomez-Sanchez CE, Fitzgerald DA, Rogers LM and Holzwarth MA: Phenotypic changes and proliferation of adrenocortical cells during adrenal regeneration in rats. Endocr Res 22: 395-400, 1996.

31. Rucinski M, Tortorella C, Ziolkowska A, Nowak M, Nussdorfer GG and Malendowicz LK: Steroidogenic acute regulatory protein gene expression, steroid-hormone secretion and proliferative activity of adrenocortical cells in the presence of proteasome inhibitors: In vivo studies on the regenerating rat adrenal cortex. Int J Mol Med 21: 593-597, 2008.

32. Hochol A, Markowska A, Meneghelli V, Jedrzejczak N, Majchrzak M, Nowak M, Nussdorfer GG and Malendowicz LK: Effects of neurotensin and bombesin on the secretory and proliferative activity of regenerating rat adrenal cortex. Histol Histopathol 14: 1073-1078, 1999.

33. Markowska A, Nussdorfer GG and Malendowicz LK: Effects of bombesin and neuromedin-B on the proliferative activity of the rat adrenal cortex. Histol Histopathol 8: 359-362, 1993.

34. Amano O, Kanda T, Ono T and Iseki S: Immunocytochemical localization of rat intestinal $15 \mathrm{kDa}$ protein, a member of cytoplasmic fatty acid-binding proteins. Anat Rec 234: 215-222, 1992.

35. Iseki S, Amano O, Kanda T, Fujii $\mathrm{H}$ and Ono T: Expression and localization of intestinal $15 \mathrm{kDa}$ protein in the rat. Mol Cell Biochem 123: 113-120, 1993.

36. Landschulz KT, Pathak RK, Rigotti A, Krieger M and Hobbs HH: Regulation of scavenger receptor, class B, type I, a high density lipoprotein receptor, in liver and steroidogenic tissues of the rat. J Clin Invest 98: 984-995, 1996.

37. Temel RE, Trigatti B, DeMattos RB, Azhar S, Krieger M and Williams DL: Scavenger receptor class B, type I (SR-BI) is the major route for the delivery of high density lipoprotein cholesterol to the steroidogenic pathway in cultured mouse adrenocortical cells. Proc Natl Acad Sci USA 94: 13600-13605, 1997.

38. Rodrigueza WV, Thuahnai ST, Temel RE, Lund-Katz S, Phillips MC and Williams DL: Mechanism of scavenger receptor class B type I-mediated selective uptake of cholesteryl esters from high density lipoprotein to adrenal cells. J Biol Chem 274: 20344-20350, 1999.

39. Out R, Hoekstra M, Spijkers JA, Kruijt JK, van Eck M, Bos IS, Twisk $J$ and Van Berkel TJ: Scavenger receptor class B type I is solely responsible for the selective uptake of cholesteryl esters from HDL by the liver and the adrenals in mice. J Lipid Res 45: 2088-2095, 2004.

40. Azhar S, Leers-Sucheta S and Reaven E: Cholesterol uptake in adrenal and gonadal tissues: the SR-BI and 'selective' pathway connection. Front Biosc 8: 998-1029, 2003.

41. Hołlysz M, Derebecka-Hołysz N and Trzeciak WH: Transcription of LIPE gene encoding hormone-sensitive lipase/cholesteryl esterase is regulated by SF-1 in human adrenocortical cells: involvement of protein kinase A signal transduction pathway. J Mol Endocrinol 46: 29-36, 2011.

42. Cook KG, Lee FT and Yeaman SJ: Hormone-sensitive cholesterol ester hydrolase of bovine adrenal cortex: identification of the enzyme protein. FEBS Lett 132: 10-14, 1981.

43. Beckett GJ and Boyd GS: Purification and control of bovine adrenal cortical cholesterol ester hydrolase and evidence for the activation of the enzyme by a phosphorylation. Eur J Biochem 72: 223-233, 1977. 
44. Cook KG, Yeaman SJ, Strålfors P, Fredrikson G and Belfrage P Direct evidence that cholesterol ester hydrolase from adrenal cortex is the same enzyme as hormone-sensitive lipase from adipose tissue. Eur J Biochem 125: 245-249, 1982.

45. Yeaman SJ: Hormone-sensitive lipase-new roles for an old enzyme. Biochem J 379: 11-22, 2004 .

46. Kraemer FB and Shen WJ: Hormone-sensitive lipase: control of intracellular tri-(di-)acylglycerol and cholesteryl ester hydrolysis. J Lipid Res 43: 1585-1594, 2002.

47. Okazaki H, Igarashi M, Nishi M, Sekiya M, Tajima M, Takase S, Takanashi M, Ohta K, Tamura Y, Okazaki S, Yahagi N, Ohashi K, Amemiya-Kudo M, Nakagawa Y, Nagai R, Kadowaki T, Osuga J and Ishibashi S. Identification of neutral cholesterol ester hydrolase, a key enzyme removing cholesterol from macrophages. J Biol Chem 283: 33357-33364, 2008.

48. Kraemer FB, Shen WJ, Harada K, Patel S, Osuga J, Ishibashi S and Azhar S: Hormone-sensitive lipase is required for high-density lipoprotein cholesteryl ester-supported adrenal steroidogenesis. Mol Endocrinol 18: 549-557, 2004.

49. Osuga J, Ishibashi S, Oka T, Yagyu H, Tozawa R, Fujimoto A, Shionoiri F, Yahagi N, Kraemer FB, Tsutsumi O and Yamada N: Targeted disruption of hormone-sensitive lipase results in male sterility and adipocyte hypertrophy, but not in obesity. Proc Natl Acad Sci USA 97: 787-792, 2000

50. Shen WJ, Patel S, Natu V, Hong R, Wang J, Azhar S and Kraemer FB: Interaction of hormone-sensitive lipase with steroidogenic acute regulatory protein: facilitation of cholesterol transfer in adrenal. J Biol Chem 278: 43870-43876, 2003.

51. Ohta K, Sekiya M, Uozaki H, Igarashi M, Takase S, Kumagai M, Takanashi M, Takeuchi Y, Izumida Y, Kubota M, Nishi M, Okazaki H, Iizuka Y, Yahagi N, Yagyu H, Fukayama M, Kadowaki T, Ohashi K, Ishibashi S and Osuga J: Abrogation of neutral cholesterol ester hydrolytic activity causes adrenal enlargement. Biochem Biophys Res Commun 404: 254-260, 2011.
52. Meiner VL, Cases S, Myers HM, Sande ER, Bellosta S, Schambelan M, Pitas RE, McGuire J, Herz J and Farese RV Jr: Disruption of the acyl-CoA: cholesterol acyltransferase gene in mice: evidence suggesting multiple cholesterol esterification enzymes in mammals. Proc Natl Acad Sci USA 93: 14041-14046, 1996.

53. Hammer GD and Ingraham HA: Steroidogenic factor-1: its role in endocrine organ development and differentiation. Front Neuroendocrinol 20: 199-223, 1999.

54. Parker KL and Schimmer BP: Steroidogenic factor 1: a key determinant of endocrine development and function. Endocr Rev 18: 361-377, 1997.

55. Muscatelli F, Strom TM, Walker AP, Zanaria E, Récanx D, Meindl A, Bardoni B, Guioli S, Zehetner G, Rabl W, Schwarz HP, Kaplan JC, Camerino G, Meitinger T and Monaco AP: Mutations in the DAX-1 gene give rise to both X-linked adrenal hypoplasia congenita and hypogonadotropic hypogonadism. Nature 372: 672-676, 1994.

56. Lala DS, Rice DA and Parker KL: Steroidogenic factor I, a key regulator of steroidogenic enzyme expression, is the mouse homolog of fushi tarazu-factor I. Mol Endocrinol 6: 1249-1258, 1992.

57. Beuschlein F, Keegan CE, Bavers DL, Mutch C, Hutz JE, Shah S, Ulrich-Lai YM, Engeland WC, Jeffs B, Jameson JL and Hammer GD: SF-1, DAX-1, and acd: molecular determinants ofadrenocortical growth and steroidogenesis. Endocr Res 28: 597-607, 2002. 